\title{
Phytochemicals and Elemental Analysis of Methanol Leave Extract of Peppermint Tea (Mentha Piperita L.)
}

\author{
Gadaka M. A. ${ }^{1 *}$, Muazu A. B. ${ }^{2}$ and Muhammad I.U. ${ }^{2}$ \\ ${ }^{1}$ Department of Biochemistry, Faculty of Science, University of Maiduguri. Nigeria \\ ${ }^{2}$ Department of Biochemistry, College of Medical Sciences, Yobe State University, Damaturu. Yobe State, \\ Nigeria. \\ *Correspondence author: E-mail:madodo232@gmail.com
}

\begin{abstract}
The species Mentha piperita L. (Peppermint tea) is an aromatic perennial glabrous and strongly scented herb. It is one of the most popular and widely consumed single ingredient herbal teas, or tisanes. This study evaluate the phytochemicals constituents and elemental compositions of methanolic leaves extract of peppermint tea. Qualitative phytochemical screening revealed the presence of alkaloid, flavonoids, glycosides, saponin, steroids, tannins, terpenoids and total phenolic compounds, while quantitative analysis shows terpenoids $>$ total phenolic compounds $>$ flavonoids $>$ alkaloids $>$ glycosides $>$ tannins $>$ steroids $>$ saponins. Elemental analysis revealed the presence of potassium (K) $116.67 \pm 0.00 \mathrm{mg} / \mathrm{kg}$, Calcium (Ca) $96.67 \pm 9.95 \mathrm{mg} / \mathrm{kg}$, Sodium (Na) $93.33 \pm 0.00 \mathrm{mg} / \mathrm{kg}$, Iron $(\mathrm{Fe}) 77.53 \pm 0.50 \mathrm{mg} / \mathrm{kg}$, Copper $(\mathrm{Cu}) 49.13 \pm 5.15 \mathrm{mg} / \mathrm{kg}$, Manganese $(\mathrm{Mn}) 15.33 \pm 0.75 \mathrm{mg} / \mathrm{kg}$, Magnesium (Mg) $9.33 \pm 4.00 \mathrm{mg} / \mathrm{kg}$, and Zinc $(\mathrm{Zn}) 0.80 \pm 0.30 \mathrm{mg} / \mathrm{kg}$. Thus this study shows peppermint plant to be of high nutritional value and contain medicinally important bioactive compounds.
\end{abstract}

Keywords: Phytochemicals; Elemental Analysis; Peppermint; Methanol and Leave Extract

DOI: $10.7176 / \mathrm{FSQM} / 108-07$

Publication date:May $31^{\text {st }} 2021$

\subsection{Introduction}

Peppermint tea (Mentha piperita L.) is a perennial herb native to Europe, naturalized in the northern USA and Canada and cultivated in many parts of the world. It is a hybrid of spearmint (Mentha spicata L.) and water mint (Mentha aquatica L.), peppermint grows particularly well in areas with high water-holding capacity soil. The genus Mentha belongs to the family lamiaceae (labiatae), consisting of about 25-30 species (Ali et al., 2002). Peppermint tea (Mentha piperita L.) is among the most popular single ingredient herbal teas. The list of supported benefits and uses of peppermint as a folk remedy or in complementary and alternative medical therapy includes: biliary disorders, dyspepsia, enteritis, flatulence, gastritis, intestinal colic, and spasms of the bile duct, gallbladder and gastrointestinal (GI) tract.

About $80 \%$ of the world's population currently relies on indigenous or traditional medicines for their primary health needs, and most of this therapy involves the use of plant extracts, often in aqueous solutions (Zhang, 2002). Of the plant-based foods used as medicines, none have received more attention as a group than herbal remedies (Dubick, 1996). The medicinal value of plant lies in some chemical substances that produce a definite physiological action on the human body (Amin et al., 2013). Only a small percentage of plants species have been investigated phytochemically and fraction submitted to biological screening is even smaller. Peppermint tea is used to treat coughs, bronchitis and inflammation of oral mucosa and throat.

In addition, the use of herbal medicine for treatment of diseases and infection is as old as mankind. World Health Organization supports uses of traditional medicines provided they are proven to be efficacious and relatively safe. Mentha piperita L. (Family: lamiaceae; synonym: M. balsamea wild; commonly known as peppermint) is a natural hybrid of ( $M$. aquatica and $M$. spicata), a perennial herb, propagating vegetatively, spreading quickly by underground runner (raining season) and through stolons (winter). It is a well-known and important medicinal plant widely used in several indigenous system of medicines, with immense therapeutic uses (oldest known medicinal plant species, "medicinal plant of the year 2004" and known as "heirba Buena" meaning good herb). Apart from possessing other potential uses (as flavoring agent from chewing gum to after dinner mints), in cosmetics and pharmaceutical products. Reed et al (2008) reported that peppermint scent can be used as an effective adjunct to decrease appetite, decrease hunger craving, and consume fewer calories, which may lead to weight reduction and greater overall health.

Recently, there is increases in the consumption of peppermint leaves, hence the need to analyze its phytochemical constituents as well as the elemental compositions. As it will enable the consumers to be aware of the health benefits, uses or side effect of its consumption. 


\subsection{Materials and methods}

2.1 Collection and Extraction of the Plant Material

The whole plant of Mentha piperita L. (peppermint tea) was obtained from Sharada (Rafin Gadon Kaya) Kano Municipal local government area of Kano state, Nigeria. It was authenticated with a voucher number by a botanist from the Plant Science Department of Bayero University, Kano. It was shade dried to a constant weight, and the leaves were separated from its stalk, pulverized and sieved using a $0.5 \mathrm{~mm}$ mesh size. The fine powdered samples obtained was stored in air tight container at an ambient temperature until the analysis.

The ground plant material was successively extracted with methanol in a Soxhlet extractor. Twenty gram (20g) of the pulverized sample was packed in a cheesecloth bag known as extraction thimble. Methanol was used for the extraction process until a clear solvent was obtained from the thimble. The filtrate was collected and solvent evaporated to dryness.

\subsection{Phytochemical Screening}

Phytochemical tests were carried out by using the standard methods of Sofowora (1993), Parekh and Chanda (2009), Trease and Evans (1989) and El- Olemyl et al (1994).

\subsection{Elemental Determination}

Five gram $(5.0 \mathrm{~g})$ of the prepared samples were air dried, ground in an agate mortar and was placed in quartz crucibles for dry ashing and mineralized thermally in a muffle furnance at $450^{\circ} \mathrm{C}$ for $12 \mathrm{hrs}$. The mineralized samples was then acid digested by dissolving in $20 \mathrm{ml}$ of $1: 1(\mathrm{v} / \mathrm{v})$ concentrated $\mathrm{HNO} 3$ and $\mathrm{HCl}$ acids in $100 \mathrm{ml}$ volumetric flask. The flask was then heated in an electro thermal heater with gentle swirling till digestion completed by evolution of white fumes. The cooled digests was filtered through Whatman No 1 filter paper into $50 \mathrm{ml}$ volumetric flask and was diluted to $50 \mathrm{ml}$ mark with de-ionized water. The heavy metals content of the samples were determined using the atomic absorption spectrophotometer (AAS) and calculated using the relation $y=m x+c$ from calibration of each metal standard (AOAC, 2005).

\subsection{Results and discussion}

\subsection{Results}

Preliminary phytochemical screenings of leave extract of Mentha piperita was carried out for the identification and quantification of alkaloids, flavonoids, glycosides, saponins, steroids, tannins, terpenoids and total phenolic compounds. The results revealed the presence of all these chemical constituents with terpenoids having the highest quantity while saponins is the least phytochemical present s presented in table1 below.

Table 1: Qualitative and Quantitative phytochemical Screenings of Metabolic Leave Extract of peppermint

\begin{tabular}{ccc} 
& peppermint & Quantitative(mg/g) \\
\hline Phytochemical constituents & Qualitative & $18.87 \pm 0.05$ \\
Alkaloids & ++ & $24.07 \pm 0.05$ \\
Flavonoids & ++ & $12.57 \pm 0.05$ \\
Glycosides & ++ & $0.04 \pm 0.00$ \\
Saponins & + & $0.30 \pm 0.00$ \\
Steroids & + & $4.73 \pm 0.02$ \\
Tannins & + & $72.90 \pm 0.10$ \\
Terpenoids & +++ & $43.87 \pm 0.20$
\end{tabular}

Key: +++ "Highly present", ++ "Moderately present", + "Low", the Results were expressed as mean \pm standard deviation of triplicate $(n=3)$ measurements.

Table 2 shows the mineral components of peppermint leaves extracts. Potassium was observed to be dominant in the leaves with an amount, followed by Calcium, then Sodium, then Iron, then Copper, followed by Manganese, then Magnesium with Zinc having the least quantity. 
Table 2: Elemental composition of peppermint methanol extract of leaves

\begin{tabular}{cc}
\hline Elements & Quantity $(\mu \mathrm{g} / 100 \mathrm{~g})$ \\
\hline Calcium $(\mathrm{Ca})$ & $96.67 \pm 9.95$ \\
Copper $(\mathrm{Cu})$ & $49.13 \pm 5.15$ \\
Iron (Fe) & $77.53 \pm 0.50$ \\
Potassium (K) & $116.67 \pm 0.00$ \\
Magnesium (Mg) & $9.33 \pm 4.00$ \\
Manganese (Mn) & $15.33 \pm 0.75$ \\
Sodium (Na) & $93.33 \pm 0.00$ \\
Zinc (Zn) & $0.80 \pm 0.30$
\end{tabular}

Results were expressed as mean \pm standard deviation of triplicate $(n=3)$ measurements.

\subsection{Discussion}

The present study showed the presence of alkaloids, flavonoids, glycosides, saponins, steroids, tannins, terpenoids and total phenolic compounds in the methanol mint leaf extract, with high contents of terpenoids, total phenolic compounds and flavonoids than alkaloids, glycosides and tannins while steroids and saponins were found to be in lower amount. Terpenoids was reported to have medicinal properties such as anti-carcinogenic (e.g. perilla alcohol), antimalarial (e.g. artemisinin), anti-ulcer, hepaticidal, antimicrobial or diuretic (e.g. glycyrrhizin) activity. (Langenheim, 1994). Phenolic compounds are famous group of secondary metabolites with wide pharmacological activities. Phenolic possesses diverse biological activities such as antiulcer, antiinflammatory and antioxidant (Lin et al., 2003), cytotoxic and antitumor, antispasmodic, and antidepressant activities were also reported.

Flavonoids have also been reported to be potent antioxidant and free radicals scavengers capable of protecting cell membranes from damage (Wasagu and Laval, 2005). In vitro studies have shown that flavonoids have antiallergic, anti-inflammatory, anti- microbial, anti-cancer and hypolipidemic effects (Wang et al., 2004). Alkaloids have many pharmacological activities including antihypertensive effects (many indole alkaloids), antiarrhythmic effect (quinidine, spareien), antimalarial activity (quinine), and anticancer actions (dimeric indoles, vincristine and vinblastine). Some alkaloids have stimulant property as caffeine and nicotine, morphine are used as the analgesic and quinine as the antimalarial drug (Rao et al., 1978).

Tannins were reported to have therapeutic uses due to their anti-inflammatory, anti-fungal, antioxidant and healing properties. Extensive research has been carried out into the membrane-permeabilising, immunostimulant, hypocholesterolaemic and anticarcinogenic properties of saponins and they have also been found to significantly affect growth, feed intake and reproduction in animals (Sachin, 2013).

Several studies have reported the presence of various elements in plant extracts. These elements are present at varying concentrations in different parts of the plants, especially in roots, seeds and leaves which are used as a dietary item as well as ingredient in the medicinal preparation (Hamed et al., 2008). Potassium is very vital in regulation of water and electrolyte balance and acid-base balance in the body, as well as responsible for nerve action and functioning of the muscles. Deficiency of potassium leads to muscle paralysis. Calcium is essential for bone and teeth formation and development, blood clotting and for normal functioning of heart, nervous system and muscles. It plays an important role in building and maintaining strong bones and teeth, large part of human blood and extracellular fluids. Calcium deficiency can lead to ricket, osteomalacia and tooth decay. Sodium is important mineral element that aids the transmission of nerve impulses as well as maintenance of osmotic balance of the cells. Sodium has an important role in maintaining the water balance within cells and in the function of both nerve impulse and muscles. Sodium also helps in maintenance of normal acid-base balance. Deficiency of sodium may lead to dehydration or muscle cramp.

Iron is very important in the formation of haemoglobin in red blood cells and deficiency of iron leads to anaemia. Peppermint could be used to improve the anaemic condition of a patient (Wilson et al., 2003). Copper is very vital in diet because it is involved in the proper usage of iron and especially for the synthesis of cytochrome oxidase, which contains both iron and copper. Excess copper can lead to jaundice (Wilson's disease)

Manganese are essential for normal functioning of central nervous system and are a good anti-oxidant. Magnesium helps in maintaining a normal heart rhythm and is sometimes given intravenously to reduce the chance of atrial fibrillation and cardiac arrhythmia (Volpe, 2008). Zinc is important in wound healing and also functions as an antioxidant. It is essential in the activation of certain enzymes. These include dehydrogenase, 
alkaline phosphatese and carboxypeptidase. Zinc containing organic compounds is employed as astringent and anti-fungal agents. It is therefore, aids wound healing and metabolism of nucleic acid and insulin. Zinc in excess causes anaemia and if deficient in the body can lead to dermatitis (Salgueiro et al., 2001).

\subsection{Conclusion}

The research revealed peppermint leaves to be rich in phytoconstituents. However, excess consumption of this leaves as food by both humans and animals can lead to increase in level of mineral element in the body which can result to metabolic diseases. Therefore, it should be used with caution until scientifically proven to be safe.

\section{Reference:}

Ali, M.S., Saleem, M., Ahmad, W., Parvez, M., and Yamdagni, R. (2002). A Chlorinated monoterpene keton, acylated B-sitosterol glycosides and a flavanone glycoside from Mentha longigolia (Lamiacaea). Phytochemistry, 59: 889-895.

Amin, M.M., Sawhney, S.S. and Jassal, M.M.S, (2013). Qualitative and Quantitative Analysis of Taraxacum Officinale. Wudpecker Journal of Pharmacy and pharmacology, 2: 1-5.

AOAC. (2005). Official Methods of Analysis International, 18th edition, Association of Official Analytical Chemists, Washington DC.USA pp. 6-8.

Dubick, M.A. (1996). Historical Perspectives on the use of herbal preparations to promote health. J Nutr 116:1348-1354.

El-Olemy, M.M., Al-muhdtadi, F.J. and Afifi, A.A. (1994). Experimental Phytochemistry. A laboratory manual. Published by King Saudi University Prees $5^{\text {th }}$ ed. Pp 247.

Ghasemzadeh, A., Hawa, Z., Jaafar E. and Asmah, R. (2011). Effects of solvent type on phenolics and flavonoids content and antioxidant activities in two varieties of young ginger (Zingiber officinale Roscoe) extracts. Journal of Medicinal Plants Research. 5(7): 1147-1154.

Hamed, S.Y., El Hassan, N.M., Hassan, A.B., Eltayeb, M.M. and Babiker, E.E. (2008) Nutritional Evaluation and Physiochemical Properties of Processed Pumpkin ( Telfairia occidentalis Hook) Seed Flour. Pakistan Journal of Nutrition, 7(2): 330-334.

Langenheim J.H. (1994). A phytocentric overview of their ecological roles. J Chem Ecol. 20(6):1223-80.

Lin, C.C, Wu, S.J, Chang, C.H and Nu, L.T. (2003). Antioxidant activity of Cinnamomum cassia. Phytoth Res. 17:726-730.

Parekh, J. and Chanda, S. U. (2007). In- vitro antimicrobial activity and phytochemical analysis of some Indian medicinal plants. Turk J Biol. 31:53-58

Reed, J. A. (2008). Effects of peppermint scent on appetite control and caloric intake. Appetite. doi:10.1016/J.appet.2008.04.196.

Sachin, V. (2013). "Anti-inflammatory and anti-arthritic activity of type-A procyanidine polyphenols from bark of Cinnamomum zeylanicum in rats. Beijing Academy, Food Sciences and Human Wellness; vol.2; Pages 59-67.

Salgueiro, M.J., Krebs, N. and Zubillaga M. B. (2001). Zinc and diabetes mellitus: is there a need of zinc supplementation in diabetes mellitus patients? Biological Trace Element Research, 81(3): 215-228.

Sofowora, A. (1993). Medicinal Plants and Medicine in Afric. John Willey Spectrum, Ibadan-Nigeria. 2: 81 85.

Trease, G.E. and Evans, W.C. (1989). Pharmacognosy. A physician guide to herbal medicine, 11edn. Ballere Tindal, London, UK, pp 530.

Volpe, S. L. (2008). Magnesium, the metabolic syndrome, insulin resistance, and type 2 diabetes mellitus. Critical Reviews in Food Science and Nutrition. 48(3): 293-300.

Wang, Y.H., Chao, P.D., Hsiu S., Wen, K.C. and Hou, Y.C. (2004). Lethal quercetin-digoxin interaction in pigs. Life Sci.; 74:1191-1197.

Wasagu, F. and Laval, M. (2005). Evaluation of Phytochemical and Antioxidant Levels and microbial screening of Agents Leaf Extract of Aleo Vera (Aleo Barbadensis Miller). Bio and Enviroment. Sci Jnl. 2:21-25.

Wilson, J. H. Lindquist, S. C. Grambow, E. D. Crook, and J. F. Maher, J. G. (2003).Potential role of increased iron stores in diabetes, The American Journal of the Medical Sciences. 325(6): 332-339.

Zhang, X. (2002). WHO Traditional Medicine Strategy 2002-2005. World Health Organization: Geneva, Switzerland. 